Knowledge Horizons - Economics
"Dimitrie Cantemir" Christian University
Volume 8, No. 1, pp. 148-150
P-ISSN: 2069-0932, E-ISSN: 2066-1061
O2016 Pro Universitaria
www.orizonturi.ucde.ro

\title{
THE CIRCULAR ECONOMY IN THE EUROPEAN UNION
}

\section{Anca COSTEA-DUNĂRINTUU}

International Business and Economics Faculty, "Dimitrie Cantemir" Christian University, Bucharest, E-mail: anca.dunarintu@gmail.com

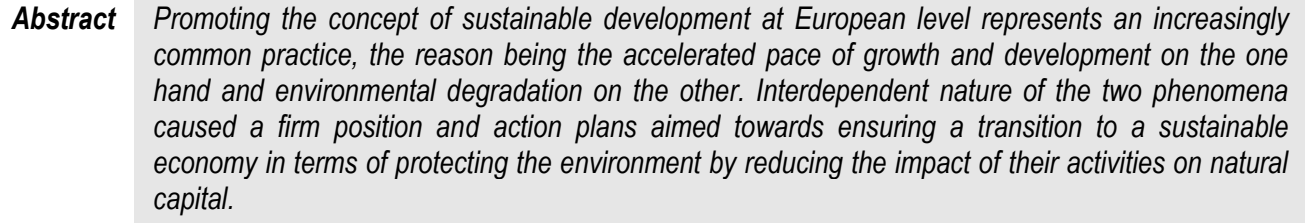

Promoting the concept of sustainable development at European level represents an increasingly hand and environmental degradation on the other. Interdependent nature of the two phenomena caused a firm position and action plans aimed towards ensuring a transition to a sustainable economy in terms of protecting the environment by reducing the impact of their activities on natural capital.
Key words: Circular economy, natural resources waste, efficiency

JEL Codes:

Q01, Q21, Q57

\section{Introduction}

Promoting the concept of sustainable development at European level represents an increasingly common practice, the reason being the accelerated pace of growth and development on the one hand and environmental degradation on the other. Interdependent nature of the two phenomena caused a firm position and action plans aimed towards ensuring a transition to a sustainable economy in terms of protecting the environment by reducing the impact of their activities on natural capital.

Integrating the concept of efficient use of natural resources and changing business processes requires a wide approach that starts from the involvement of decision makers, owners of interests, not least the manufacturers and consumers.

Designing economic solutions according to ecological principles involve increased effort by global economic actors. However, society and ways of production and consumption do not lead us to an improvement in growth- environment quality relationship. It is therefore necessary to intervene in order to continue to cope with the increased demands and pressures that come into this.

Circular economy is supporting this approach routed through a series of measures and proposals consistent with the objectives of a sustainable economy.

One of the ways we can continue to generate economic growth and development at a sustainable level is to find business solutions that can enable us to satisfy the needs of the environment without causing major imbalances.

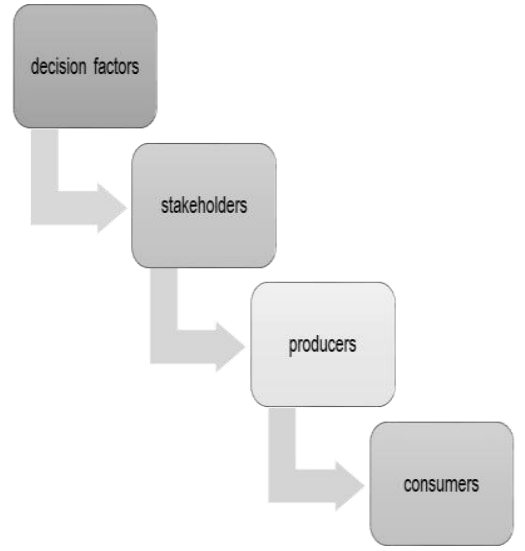

(Source: Own representation)

Figure 1. Involvement level for economic evolvement to sustainability

\section{Europe $\mathbf{2 0 2 0}$ Strategy-sustainable growth}

Europe 2020 Strategy sets out a number of objectives in the field of environment designed to ensure within this timeframe a change in current models regarding the impact on natural capital. The main objective of this strategy is represented by three essential features of economic growth and development process:

$\rightarrow$ Smart growth;

$\rightarrow$ Sustainable growth;

$\rightarrow$ Inclusive growth.

A green growth strategy is centered on mutually reinforcing aspects in the economic and environmental policy, taking into account the total value of natural capital as a factor of production and its role in growth. It focuses on cost-effective ways to mitigate 
environmental pressures to perform a transition to new models of economic growth that will avoid crossing critical thresholds in terms of the environment locally, regionally and globally.

The necessity of adopting a sustainable model derived from the intensification of certain trends that materializes through: (European Commission, 2012)

1. the increasing dependence on fossil fuels, with implications for increasing the level of dependency and vulnerability of consumers and businesses in the face of threats such as price changes, economic security and who are responsible for environmental degradation; 2. poor management of natural resources, and increased current consumption patterns are unsustainable at the scale required by the current population. Much of this, however, is due to inefficient production and consumption;

3. climate change, caused mainly by the increasing emissions of greenhouse effect gases. Global atmospheric concentrations of greenhouse gases continue to rise. Without major policy changes, they are projected to double in the next 50 years, with an increase in emissions, mainly from developing countries.

4. competitiveness meeting features an ever expanding global market, will eventually come to respect ecological efficiency characteristics of the goods and services they possess. In this process, innovation will be a invaluable contribution.

The targets that are envisioned by the 2020 Strategy are presented in figure 2 .

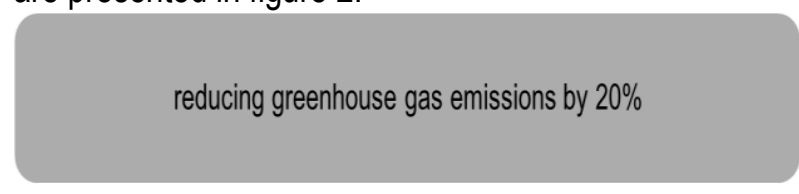

increasing the share of renewables in final energy consumption to $20 \%$

$$
20 \% \text { increase in energy efficiency }
$$

(Source: Own representation upon European Commission, 2012)

Figure 2. 20-20-20 objectives for sustainable growth

\section{The circular economy in the European Union}

The classic model of production and consumption is characterized by a linear approach which involves the following stages:

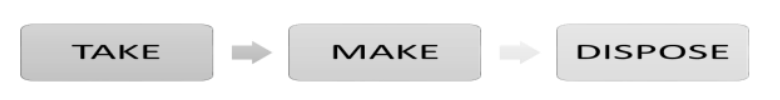

(Source: Own representation, based The Ellen MacArthur Foundation's report on the Economics of a Circular Economy)

Figure 3. Linear economy

Sustainable production and consumption refers to the use of products and services that meet basic needs, improving quality of life while minimizing use of natural resources and toxic substances and emissions of waste and pollutants over the life cycle of the product or service, so as not to jeopardize the future generations.

Also, if the business sector, this concept refers to the potential to transform environmental challenges in economic opportunities. This can be translated as follows: "to do more with fewer resources."

The challenge is the ability to improve the overall environmental performance of products over their life cycle, boost demand for products and better production technologies and to help consumers make informed choices.

In terms of consumption that can reach 82 Billion tones by 2020 (Ellen M., 2013), which represents the amount that gets to be processed and consumed, the trend of use and exploitation over the recent years, especially in developed countries has been dependent upon the reduced price of the resources (McKinsey Global Institute, 2011), the growth and development processes being a result of the existing conditions speculation.

Graph 1. Global resource extraction
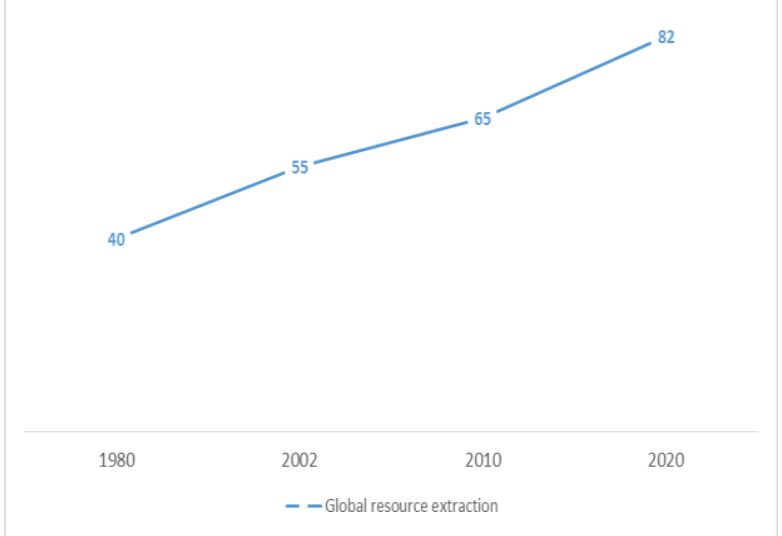

(Source: Own representation, based The Ellen MacArthur Foundation's report on the Economics of a Circular Economy)

It is these conditions which represented an attractive climate and favorable in the short term the business 
has ultimately led to overexploitation and waste generation.

This same type of economy generates products with limited lifespan, these features printing an unsustainable character upon consumption. For example at the European level there are used annually around 15 million tons of materials per person, while generating 4.5 tons of waste per year, half of which goes to landfill (European Commission).

The circular economy refers to the industrial character of the economy, which is characterized by Braungart and William as:

- self-sustainable;

- based on renewable energy;

- minimizes the use and generation of toxic substances;

- reduces waste by implementing this measure in the design process.

A further point to consider, the transition to such a type of economy can provide value maintaining it for as long as possible, with low waste levels, thus ensuring sustainability, lower emissions, resource efficiency and increased competitiveness.

Life product extension, creating products which are more durable, reusable, repairable, which can respond to current needs is one of the main objectives of this type of economy.

Also rethinking the paradigm based on supply chains focused on cost by incorporating value-oriented ones, it is a way to bring awareness to the forefront of new approaches to sustainable development and supported through a circular economy.

According to the European Commission, in the report "The circular economy- connecting, creating and preserving value," though the efforts are oriented towards such an economy, the policies and measures adopted at European level are translated into practice through action plans, the strategic directions that need to be respected, there are still some technical, social, political and economic barriers such as:

- companies are often not aware or do not have the ability or knowledge to choose solutions of circular economy;

- systems, infrastructure, business models and technology of today can lock the economy into a linear model;

- investment in efficiency measures or innovative business models remain insufficient and are considered risky and complicated;

- the demand for sustainable products and services can remain low, especially if they involve changes in behavior;

- often, the prices reflect actual costs incurred by the company for the consumption of resources and energy;
- signals political transition to a circular economy are not strong enough and consistent.

\section{Conclusions}

Numerical growth and increased economic activity has led mankind to large scale environmental changes with a major impact on the state of ecosystems and biodiversity. Their manifestation and the prospect of continuing their production is explained, inter alia, by reference to the difference in scale between the time of nature and time of the economy. Changing the environment through climate change occurs after several decades of greenhouse gas pollution.

Without identifying viable solutions in terms of reducing the impact of human activities on the environment we will face extinction of life support as the natural capital. The circular economy proposes the solution for a transition to a cleaner and healthier environment, but depends only on who will succeed to put this into practice following the principles promoted through this concept.

\section{References}

1. Costea-Dunărințu, A. (2014). Ecoantreprenoriat, ed. ProUniversitaria.

2. McDonough W. and Braungart, M. (2002). Cradle to Cradle: remaking the way we make things, New York: North Point Press.

3. McKinsey Global Institute's November 2011 report Resource Revolution.

4. The Ellen MacArthur Foundation's report on the Economics of a Circular Economy.

5. European Commission, Towards a circular economy: A zero waste programme for Europe, 2014.

6. European Commission, Closing the loop - An EU action plan for the Circular Economy, 2015.

7. European Environment Agency, Well-being and the environment Building a resource-efficient and circular economy in Europe, 2014. 